\title{
Nos movimentos do discurso: sentidos e sujeitos em espiral*
}

\author{
Ludmila Ferrarezi** $^{* *}$
}

Resumo: Nesse artigo, buscamos analisar como os sujeitos bibliotecários enunciam sobre a biblioteca escolar, em um blog e uma lista de discussão. Para tanto, apresentamos, inicialmente, algumas considerações sobre a teoria do discurso, que nos possibilitaram analisar a constituição do discurso, flagrar as regularidades e deslocamentos de sentidos sobre a biblioteca escolar, desconstruindo a literalidade dos sentidos dominantes sobre essa instituição, que circulam na chamada sociedade da informação.

Palavras-chave: discurso; internet; biblioteca escolar.

Ai, palavras, ai, palavras, que estranha potência, a vossa! Ai, palavras, ai, palavras, sois de vento, ides no vento no vento que não retorna, e, em tão rápida existência tudo se forma e transforma! (Meireles, 1979, p. 28).

\section{Nas trilhas do discurso: palavras em movimento}

$\mathrm{Na}$ perspectiva que adotamos para construir sentidos sobre a biblioteca escolar, trabalhar com o discurso significa procurar "compreender a língua fazendo sentido, enquanto trabalho simbólico, parte do trabalho social geral, constitutivo do homem e da sua história" (ORLANDI, 2003, p. 15). Assim, é no espaço tenso entre a língua e a história que se encontra o discurso, um conceito que, na ótica pecheuxtiana, implica pensar a língua em movimento, afastar-se da noção de transmissão de informação em direção a uma concepção de linguagem que a toma como aquilo que especifica a existência do simbólico, sendo marcada pelo ausente, o invisível e o impossível (PÊCHEUX, 1990), que constituem todo dizer, afetado sempre pelo ideológico e o político. O discurso pode ser compreendido, também, como efeito de sentidos, que estão sujeitos a deslocamentos e, ao mesmo tempo, repetições, pelo retorno da memória discursiva; ou seja, mantém-se um tenso jogo entre o mesmo (a estrutura) e o diferente (o acontecimento) (Id., 2002). Essa movência do dizer nos leva a apontar como os sentidos escapam às palavras; fugidios, eles não têm uma só morada, são muitos, mas também não podem ser quaisquer uns:

[...] o sentido de uma palavra, de uma expressão, de uma proposição, etc., não existe 'em si mesmo' (isto é, em sua relação transparente com a literalidade do

\footnotetext{
* Esse trabalho é um recorte da dissertação de mestrado "A biblioteca escolar nas teias do discurso eletrônico" (2010).

** Doutoranda na FFCLRP/USP. Bolsista de doutorado da FAPESP. Pesquisadora do E-L@DIS - Laboratório Discursivo: sujeito, rede eletrônica e sentidos em movimento, da FFCLRP/USP. E-mail: ludmila.ferrarezi@pg.ffclrp.usp.br
} 
significante), mas, ao contrário, é determinado pelas posições ideológicas que estão em jogo no processo sócio-histórico no qual as palavras, as expressões e proposições são produzidas. (PÊCHEUX, 1997, p. 160).

Essa injunção ideológica do dizer nos leva a apontar que os sentidos não estão prontos e nem são dados à priori, pois, na ciranda do discurso, sentido e sujeitos se constituem ao mesmo tempo, de formas variáveis e imprevisíveis, de acordo com as condições de produção que os sustentam e que se configuram a partir de duas perspectivas imbricadas: "em sentido estrito ela compreende as circunstâncias da enunciação, o aqui e o agora do dizer, o contexto imediato. No sentido lato, a situação compreende o contexto sócio-histórico, ideológico, mais amplo" (ORLANDI, 2006, p. 15).

Essas condições de produção do discurso, marcadas pelas disputas de interesses e as tensões decorrentes da manutenção ou ruptura com o poder, sustentam cada tomada da palavra, fazendo com que, em meio a tantos sentidos possíveis para discursivizar, por exemplo, a biblioteca escolar, alguns prevaleçam em detrimento de outros, que são interditados, mas aparecem nas bordas do dizer e, também, no silêncio, que, para nós, é tão significativo quanto a presença de palavras. Assim, muito mais do que signos virtualizados em uma tela, trabalhamos com a materialidade do funcionamento discursivo, atravessando a cortina do evidente e procurando romper com a literalidade do sentido dominante. Vejamos, a seguir, como isso funciona nos recortes analisados.

\section{Movimentos de análise: espirais de sentidos na Internet}

Considerando os textos como movimentos discursivos, buscaremos flagrar as regularidades, as repetições e os deslocamentos de sentidos sobre a biblioteca escolar, indiciando as relações tecidas entre os diferentes discursos e sujeitos presentes nos textos eletrônicos analisados. Dessa maneira, poderemos observar, em nosso corpus, as relações de poder existentes entre os sujeitos, que determinam o que é possível de ser enunciado sobre a biblioteca escolar, em um blog e em uma lista de discussão que a discursivizam.

Inicialmente, em uma postagem do blog Librarianship (AFINAL..., 2009), publicada no dia 19 de setembro de 2009, flagramos os sentidos de restrição que conferem à biblioteca uma imagem alinhada à arcaica concepção de um depósito fechado de livros. Esses dizeres circulam a partir das críticas à falta de acesso aos acervos, o que pode ser visto ver nos recortes que seguem.

Existe uma certa tendência dentro das bibliotecas - principalmente das escolares - de que nem todo acervo seja emprestado. Talvez, isto seja um sinal de que fungos, traças e mofos possam também ter acesso aos livros.

A desculpa mais usada, talvez seja a de que as crianças irão destruir o livro e por isso é melhor conservá-lo, trancafiado dentro dos armários. E nisso tudo o que mais preocupa é que essa tendência não se restringe apenas às bibliotecas.

Essa prática de restrição do empréstimo aparece nesse discurso como algo recorrente e generalizado, visto que se tornou uma "tendência", não apenas das 
bibliotecas escolares, mas de vários órgãos governamentais, que também teriam esse hábito não justificável, já que é necessária uma desculpa, um pretexto para praticá-lo. A partir dessa perspectiva, são retomados, pela memória do discurso, os sentidos historicamente empregados para falar sobre as bibliotecas, como a medieval, associada a um lugar inerte, que funciona como um armazém, cuja função seria a de resguardar e conservar os materiais, a partir de uma lógica inóspita pela qual se evitaria o manuseio; ao serem ressignificadas dessa maneira, a biblioteca escolar e sua missão não estariam direcionadas para os sujeitos-leitores, mas sim para os bens materiais alocados na biblioteca, perpetuando uma concepção restrita, na qual se inserem outras práticas como a preocupação excessiva com as atividades de organização e catalogação, em detrimento da disseminação, e a política de distribuição de livros, ao invés de outras que os dinamizassem.

Dessa maneira, a biblioteca continua assemelhando-se a uma prisão para livros (sentido flagrado em outros recortes), aos quais "fungos, traças e mofos" teriam acesso privilegiado, construindo, assim, uma imagem muito distante daquela preconizada em uma "sociedade da informação", que prega a liberdade como valor supremo. Por meio de indagações direcionadas ao seu interlocutor, o sujeito desse discurso, ocupando a posição de bibliotecário, enuncia sobre a restrição do empréstimo de forma a desautorizá-la, pois ela estaria associada a uma infração de um princípio bibliotecário que deveria ser obedecido e levado em consideração no cotidiano das bibliotecas:

De acordo com Ranganathan todo livro é para ser usado. Mas então por que nem todos são emprestados??? Por que comprar um livro e depois colocar que o mesmo não pode ser emprestado?

Esse vício 'anti-primeira lei da biblioteconomia' deveria ser extinto em âmbito nacional. Se este não for possível, dadas nossas proporções, que seja pelo menos no âmbito das bibliotecas.

Observamos, assim, através do litígio entre as normas bibliotecárias e o que é praticado nas escolas brasileiras, que esse discurso é atravessado pela heterogeneidade, a fim de desestabilizar os sentidos de restrição em relação à biblioteca, fazendo com que a proibição do empréstimo seja enunciada como algo nocivo, um "vício" que deve ser "extinto" e que é denunciado, posto em cheque pelo sujeito desse discurso; marcamos que, através de suas interrogações, o sujeito instala um furo no discurso, desautorizando-o, duvidando dos sentidos tidos como naturais, pela força da repetição, e abrindo uma brecha para a entrada de outros. Em consonância com esses sentidos discursivizados no blog estão os que circularam na lista de discussão Bibliotecários, Biblioteconomia, Bibliotecas (BIBLIOTECA..., 2008), na qual foi postada uma mensagem intitulada "Biblioteca escolar (desrespeito ao espaço)", no dia 15 de outubro de 2008, transcrita integramente a seguir:

Boa tarde colegas, tem algum tempo, que a biblioteca escolar em que trabalho vem sendo desrespeitada por coordenadores pedagógicos e professores que insistem em deixar alunos de castigo na biblioteca, estes alunos se revoltam e acabam detestando a biblioteca. É uma situação muito delicada, todos os dias 
tenho que ficar cuidando de alunos mal criados na biblioteca, que muitas vezes permanecem trancados lá durante todo o período de aula. Grata.

Assim como em outros recortes, temos aqui os sentidos que atribuem às práticas cerceadoras um caráter rotineiro, insistente e repetitório, marcadas na ordem da língua pelo uso do gerúndio e termos que expressam longa duração de tempo, delineando uma "situação muito delicada", difícil, que "vem sendo" praticada "tem algum tempo", "todos os dias", "durante todo o período de aula". Através desses sentidos imaginariza-se a biblioteca como um lugar indesejável, desrespeitado e detestável; marcado pelo castigo, como um lugar de "detenção" para "alunos mal criados", revoltados e indesejados na sala de aula, um lugar tão ruim que serviria como punição.

Como todo dizer cala outro, inferimos, por fim, que, ao ocupar este lugar de desprestígio, a biblioteca deixa de ser falada como uma instituição dinâmica, um centro de aprendizagem, aberto para a leitura prazerosa, dentre outros sentidos circulantes em outra formação discursiva. Do mesmo modo, ao construir para si a imagem daquele que vigia livros e alunos - o que pode ser observado no período: "eu tenho que ficar cuidando de alunos mal criados" -, o sujeito-bibliotecário deixa de ocupar uma posição diferente, a partir da qual ele poderia inscrever sentidos outros, que discursivizassem o movimento de livros e sujeitos na biblioteca, que transformassem esse espaço de castigo em uma possibilidade de conquista de um leitor, construindo outros discursos para a leitura e a biblioteca, que pudessem ir de encontro ao seu isolamento e submissão, as quais indiciam as práticas educativas restritas, punitivas e desestimulantes regularmente encontradas no contexto escolar.

A partir das análises empreendidas nesse artigo, pudemos observar como o discurso é atravessado por sentidos que já foram ditos e repetidos ao longo do tempo, desde a criação das bibliotecas escolares, e que, sustentados por condições de produção que revelam um ranço histórico de práticas bibliotecárias deveras burocráticas e autoritárias, são retomados e ressignificados pelos sujeitos-bibliotecários, desconstruindo e questionando os sentidos dominantes tecidos para a (supostamente) reluzente e moderna biblioteca da chamada sociedade da informação.

\section{Referências}

Afinal: empresta ou não empresta? 2009. Disponível em: <http://biblio20.wordpress.com/2009/09/19/afinal-empresta-ou-nao-empresta/>. Acesso em: 10.dez.2009.

Biblioteca escolar (desrespeito ao espaço). 2008. Disponível em: $<$ http://www.grupos.com.br/group/bibliotecarios/Messages.html?action=message\&id $=1224195744308126 \&$ year $=08 \&$ month $=10 \& / \% 5$ BBibliotecarios $\% 5 \mathrm{D} \% 20 \mathrm{BIBLIOTE}$ CA $\% 20$ ESCOLAR $\% 20 \% 28$ desrespeito $\% 20$ ao $\% 20$ espa $\%$ E $70 \% 29>$. Acesso em: 10.jun.2009.

MEIRELES, Cecília. Romance LIII ou Das palavras aéreas. In: Poesias completas. Rio de Janeiro: Civilização Brasileira, 1979.

ORLANDI, Eni. P. Análise de discurso. In: ; LAGAZZI-RODRIGUES, Suzy. (orgs.). Introdução às ciências da linguagem: discurso e textualidade. Campinas, SP: Pontes, 2006. 
. Análise de discurso: princípios \& procedimentos. 5. ed. Campinas, SP: Pontes, 2003.

PÊCHEUX, Michel. O discurso: estrutura ou acontecimento. Traduzido por Eni Puccinelli Orlandi. 3. ed. Campinas, SP: Pontes, 2002.

Semântica e discurso: uma crítica à afirmação do óbvio. Traduzido por Eni Puccinelli Orlandi [et.al.]. 3. ed. Campinas, SP: Editora da UNICAMP, 1997.

. Delimitações, inversões, deslocamentos. Cadernos de estudos linguísticos, n. 19, jul./dez. 1990. 